IS AVAILABILITY OF ARTESUNATE ASSOCIATED WITH THE PROGNOSIS OF IMPORTED

MALARIA IN SPAIN?

Authors: Daniel Camprubíi ${ }^{1 *}$, Helena Martí-Soler ${ }^{1}$, Carme Subirà $^{1}$, Elisabet Ferrer ${ }^{1}$, Jose Muñoz $^{1}$

1. Barcelona Institute for global Health (ISGlobal), Hospital Clínic - University of Barcelona, Barcelona, Spain.

*corresponding author: Daniel Camprubí, MD.

E-mail: dcamprub@clinic.cat

c/ Roselló 132, $4^{\text {th }}$ floor, 08036, Barcelona, Spain.

telephone number: +34932271852 


\section{IS AVAILABILITY OF ARTESUNATE ASSOCIATED WITH THE PROGNOSIS OF IMPORTED}

\section{MALARIA IN SPAIN?}

Dear Editor,

Although there is a lot of aspects we stil need to understand about treatment with artemisinins[1], there is no doubt about their efficacy in treating malaria. Artesunate (AS) has demonstrated its superiority against quinine for treatment of severe malaria in terms of reduction of mortality in different randomized clinical trials performed in endemic countries and subsequent meta-analysis[2-4]. Despite having been established as the first line treatment by $\mathrm{WHO}$ and several national guidelines[5,6], its full implementation in non-endemic countries has not been completed.

We performed a cross-sectional study to assess the impact of accessibility of AS for treating imported malaria in Spain. Data about malaria cases admitted in different hospitals of Spain was obtained from the public National Health System database (CMBD) from 2007 to 2017, aggregated by different autonomous communities (a firstlevel political and administrative division). Information about availability of AS was obtained through two rounds of calls to pharmacies of the non-monographic public hospitals in Spain. The primary outcome for the analysis was defined using aggregated mortality rates and a secondary outcome was defined using a composite outcome defined as death during admission or prolonged hospitalization ( $>7$ days)).

Data about availability of AS was obtained from 183 (55.1\%) of the 332 public hospitals inquired. The answer was similar regardless the hospitals size: $59.2 \%(74 / 125)$ of hospitals with $\geq 500$ beds, $55.6 \%$ (55/99) of hospitals with $200-499$ beds and $50.0 \%$ $(54 / 108)$ of hospitals with $<200$ beds $(p=0.369)$. AS was available in $45.9 \%(84 / 183)$ 
hospitals, being the first treatment option for severe malaria in $84.0 \%(68 / 81)$ of them (3 hospitals missing data). A decreasing trend in availability of AS was observed depending on the hospital size $(73.0 \%$ for $\geq 500$ beds hospitals vs $47.3 \%$ for $200-500$ beds hospitals vs $7.4 \%$ for $<200$ beds hospitals, -for-trends $<0.001$ ).

Between 2007 and 2017, 7731 malaria cases were reported, with an overall mortality of $1 \%$. A significant reduction in mortality was found when the first and the second study period were compared (1.3\% in $2007-2011$ vs $0.8 \%$ in $2012-2017, p=0.027)$. Median length of hospitalization did not differ between death and survival cases ( 5 days (IQR 2-14); 4 days (IQR 3-6), p=0.105). Age > 65 years (OR 6.8, 95\%Cl 3.6-12.6) and foreign origin (OR $4.3,95 \% \mathrm{Cl} 1.5-12.1$ ) were found to be associated with higher mortality in an adjusted regression model (Table). A decrease in the incidence of the secondary outcome was observed in those autonomous communities in which AS was introduced in at least 25\% of hospitals before 2015 (Median 30.8\% [IQR: 24.0-33.9\%] vs $20.7 \%$ [IQR: $18.7-24.8 \%], p=0.049)$.

In conclusion, availability of AS seems to be associated with a better outcome in patients with imported malaria attending Spanish hospitals. The lack of AS is especially worrying in smaller hospitals. Although these hospitals are less likely to admit severe malaria cases, usually transferred to tertiary specialized units, availability of AS in any health-care facility regardless its size is essential to ensure patients to receive an adequate treatment as soon as possible. Accessibility to health-care facilities may have an impact on mortality and prolonged hospitalization, as it could be the case of vulnearable populations such as patients of foreign origin. Our results reinforce the importance of ensuring a proper distribution and availability of AS in hospitals in nonendemic countries, as well as the need of promoting policies to optimize the access to 
health care systems for all citizens, in order to improve the outcome of imported malaria. 


\section{REFERENCES}

[1] Marco-Hernández J, Camprubí D, Aylagas C, Gupta H, Castro P.Failure of intravenous artesunate treatment for Plasmodium falciparum malaria in a splenectomized traveller: A diagnostic challenge. Travel Med Infect Dis. 2019;30:142-143.

[2] Dondorp A, Nosten F, Stepniewska K, Day N, White N. Artesunate versus quinine for treatment of severe falciparum malaria: a randomized trial. Lancet $2005 ; 366: 717-25$.

[3] Dondorp AM, Fanello Cl, Hendriksen IC, Gomes E, Seni A, Chhaganlal KD, Bojang K, Olaosebikan R, Anunobi N, Maitland K, Kivaya E, Agbenyega T, Nguah SB, Evans J, Gesase S, Kahabuka C, Mtove G, Nadjm B, Deen J, Mwanga-Amumpaire J, Nansumba M, Karema C, Umulisa N, Uwimana A, Mokuolu OA, Adedoyin OT, Johnson WB, Tshefu AK, Onyamboko MA, Sakulthaew T, Ngum WP, Silamut K, Stepniewska K, Woodrow CJ, Bethell D, Wills B, Oneko M, Peto TE, von Seidlein L, Day NP, White NJ; AQUAMAT group. Artesunate versus quinine in the treatment of severe falciparum malaria in African children (AQUAMAT): an open-label, randomised trial. Lancet 2010;376:1647-57.

[4] Sinclair D, Donegan S, Isba R, Lalloo DG: Artesunate versus quinine for treating severe malaria. Cochrane Database Syst Rev 2012:Cd005967.

[5] World Health Organization (WHO). Guidelines for the treatment of malaria, second edition. 2010 [Geneva, Switzerland].

[6] Muñoz J, Rojo-Marcos G, Ramírez-Olivencia G, Salas-Coronas J, Treviño B, Perez Arellano JL, Torrús D, Muñoz Vilches MJ, Ramos JM, Alegría I, López-Vélez R, Aldasoro E, Perez-Molina JA, Rubio JM, Bassat Q. Diagnosis and treatment of 
imported malaria in Spain: Recommendations from the Malaria Working Group of the Spanish Society of Tropical Medicine and International Health (SEMTSI). Enferm Infecc Microbiol Clin 2015; 33(6):e1-e13. 
Table - Factors associated with mortality and long hospitalization in malaria patients admitted to hospital in Spain (2007-2017).

\begin{tabular}{|c|c|c|c|c|c|}
\hline & Descriptive analysis & \multicolumn{2}{|c|}{ Bivariate analysis } & \multicolumn{2}{|c|}{ Adjusted analysis } \\
\hline & $\mathrm{n} / \mathrm{N}(\%)$ & OR $(95 \% \mathrm{Cl})$ & $p$-value & OR $(95 \% \mathrm{Cl})$ & $p$-value \\
\hline \multicolumn{6}{|c|}{ Mortality } \\
\hline \multicolumn{6}{|l|}{$\underline{\operatorname{Sex}}$} \\
\hline Male & 53/5117 (1.04\%) & & & & \\
\hline Female & $24 / 2609$ (0.92\%) & $1.12(0.69-1.83)$ & 0.628 & $1.34(0.79-2.26)$ & 0.275 \\
\hline \multicolumn{6}{|l|}{$\underline{\text { Age }}$} \\
\hline$>65$ years & $15 / 279$ (5.38\%) & $6.77(3.80-12.06)$ & $<0.001^{*}$ & $6.78(3.65-12.61)$ & $<0.001^{*}$ \\
\hline$\leq 65$ years & $62 / 7452$ (0.83\%) & & & & \\
\hline \multicolumn{6}{|l|}{ Nationality } \\
\hline Foreigner/migrant & 4/118 (3.39\%) & $3.82(1.37-10.67)$ & $0.010^{*}$ & $4.30(1.53-12.10)$ & $0.006 *$ \\
\hline Spanish & $66 / 7261$ (0.91\%) & & & & \\
\hline \multicolumn{6}{|c|}{ Secondary Outcome (mortality or $>7$ days of hospitalization) } \\
\hline \multicolumn{6}{|l|}{$\underline{\operatorname{Sex}}$} \\
\hline Male & $839 / 4196(20.00 \%)$ & & & & \\
\hline Female & $514 / 2186(23.51 \%)$ & $0.81(0.72-0.92)$ & $0.001^{*}$ & $0.83(0.73-0.94)$ & $0.004^{*}$ \\
\hline \multicolumn{6}{|l|}{$\underline{\text { Age }}$} \\
\hline$>65$ years & $122 / 234(52.14 \%)$ & $4.36(3.34-5.67)$ & $<0.001^{*}$ & $4.39(3.36-5.74)$ & $<0.001^{*}$ \\
\hline$\leq 65$ years & $1231 / 6153(20.01 \%)$ & & & & \\
\hline \multicolumn{6}{|l|}{ Nationality } \\
\hline Foreigner/migrant & $35 / 120(29.17 \%)$ & $1.59(1.06-2.37)$ & $0.022^{*}$ & $1.72(1.15-2.56)$ & $0.008^{*}$ \\
\hline Spanish & $1261 / 6134(20.56 \%)$ & & & & \\
\hline
\end{tabular}

Table - Descriptive, bivariate and multivariate analysis of factors associated with mortality and long hospitalization in malaria patients admitted to Spanish hospitals between 2007 and 2017. Primary outcome defined as mortality during hospitalization. Secondary outcome defined as death during admission or prolonged hospitalization $(>7$ days).

* Statistically significant $p$ - values. 